\title{
Indestructibilidad en el voluntarismo metafísico de Schopenhauer
}

\author{
Francisco Javier Higuero \\ Wayne State University, Detroit, USA
}

Resumen

La teoría de la indestructibilidad de la naturaleza se halla en consonancia con la concepción de la voluntad esgrimida por Schopenhauer. De hecho, la naturaleza pone de relieve que el individuo se muestra incapaz de sobrevivir a la muerte. Sin embargo, lo que resulta ser indestructible es la especie, convertida en la objetivización de la voluntad. Afirma Schopenhauer que la voluntad, considerada como la cosa en sí, pudiera muy bien ser calificada de eterna, manteniéndose fuera de los límites temporales, dentro de los cuales habría que incluir a los meros fenómenos individuales y empíricos. Para dicho pensador la verdadera esencia de la naturaleza es la voluntad universal, que no fue creada de la nada y, por consiguiente, la muerte ni tiene poder sobre ella, ni se encuentra propensa a destruirla totalmente.

Palabras clave: fenómeno, indestructibilidad, naturaleza, objetivización, Schopenhauer, voluntad.

\section{Abstract}

The theory of indestructibility of Nature is quite in tune with Schopenhauer's conception of Will. However, a look at Nature shows with unmistakable clarity that it cannot be the individual that in any shape or form survives death. What is indestructible is the species, which is the direct objectification of the will, the unchangeable and 
imperishable. Schopenhauer states that if existence in time were merely an image or representation of essential being, death would only be end in time of a time-enclosed phenomenon. Will, as thing in itself, is outside of time, timeless, eternal, since for the thing in itself there is no end in time and the concept time loses its meaning. Therefore, only phenomena are involved in the temporal process of coming into being and passing away, and not that, which manifests itself in the phenomena - the thing in itself. For Schopenhauer, the true essence of Nature, Will, was not created out of nothing. On the other hand, death does not produce total destruction.

Keywords: indestructibility, nature, objectification, phenomena, Schopenhauer, will.

U

na de las dificultades que pudiera surgir a la hora de estudiar el pensamiento de Arthur Schopenhauer quizás proceda del carácter transicional de sus disquisiciones que tratan de cubrir la separación existente entre los respectivos paradigmas filosóficos de los siglos XVIII y XIX. Dicho pensador se ve precisado a tener en cuenta el paradigma kantiano del idealismo trascendental, del que parten sus raciocinios especulativos, al tiempo que se atreve a postular propuestas metafísicas no totalmente ajenas al reconocimiento de la experiencia en cualquiera de sus modalidades y con la cual se precisa contar. ${ }^{1}$ Por consiguiente, conviene dejar establecido, desde un primer momento, que el punto de arranque de Schopenhauer se halla en el idealismo trascendental, procedente de lo expuesto, con todo lujo de detalles especulativos, por Immanuel Kant en Crítica de la razón pura. A todo esto se precisa agregar que tal vez no dejen de resultar paradójicos los planteamientos

${ }^{1}$ Los pensadores transicionales se suelen contradecir con cierta frecuencia, sobre todo cuando se esfuerzan por elaborar argumentaciones que no dejan de ser, a todas luces, relevantes. 
de Schopenhauer a comienzos del siglo XIX, en donde abundaba un clima intelectual entregado a promover una cierta metafísica renovada que valoraba las promesas derivadas de lo presuntamente escondido en la "cosa en sî". El cumplimiento de estas promesas sería abrazado a través de la autorreflexión y la labor ejercida por la historia. Para expresarlo de forma algo diferente, algunos contemporáneos de Schopenhauer pasaron del idealismo trascendental, adelantado por Kant, a la trascendencia propiamente dicha, creyendo haber descubierto en el fundamento del ser, o en su meta, un sentido hermenéutico no carente de alguna transparencia satisfactoria. Frente a tales conclusiones, Schopenhauer no llegó a aceptar ninguna trascendencia visible de carácter teleológico, porque, para él, el ser no es sino voluntad ciega, algo vital, pero asimismo opaco, sin orientarse a la realización de ningún designio. Sin embargo, semejante ausencia de teleología en la metafísica de dicho pensador no implica la destrucción definitiva y permanente de la voluntad de ser, que se halla por debajo de formas, apariencias, fenómenos y representaciones epistemológicas. Las páginas que siguen aspiran a destacar la indestructibilidad metafísica de la realidad volitiva, coincidente, en último término, con la "cosa en sí," frente a todo aquello abocado a no trascender determinadas objetivizaciones reduccionistas, aunque se presten a encontrarse repletas de rasgos fenoménicos, tal vez revestidos de ineludible necesidad empírica. Convendría puntualizar, a este respecto, que Schopenhauer no niega la apariencia realmente constatable, aunque, por otro lado, reconoce las prioridades filosóficas de la naturaleza interior de todo lo existente, imposibilitada, de por sí, para ser percibida o convertirse en un nuevo objeto de conocimiento.

De acuerdo con lo expresado en El mundo como voluntad y representación de Schopenhauer, lo real, correspondiente a lo que Kant denomina la "cosa en sí," se materializaría en la voluntad, consistente en algo más hondo y profundo que cualquier manifes- 
tación especulativa de lo entendido por razón. Hasta cierto punto, la voluntad no deja de ser una cierta ansia ciega, un deseo que se agazapa detrás de todo lo existente, pero sin trazar fin alguno propenso a ser alcanzado. Dicha opacidad voluntarista esgrimida por Schopenhauer se presta a ser caracterizada como irracional, aunque, sin embargo y paradójicamente, impulsa a razonar. A su vez, semejante oscuridad, convertida en rasgo propio de la voluntad, contrasta con la claridad que trataban de buscar los raciocinios de Kant. En conformidad con lo explicado por Francisco Giménez Gracia en La leyenda dorada de la filosofía, la voluntad es, para Schopenhauer, la verdadera y única causa de todo lo que aparece ante la conciencia. Tal posicionamiento nunca lo hubiera esgrimido Kant, al referirse al númeno o la "cosa en sí," que más bien se caracterizaría, en todo caso, como un residuo no desaparecido, después de aplicar las correspondientes categorías epistemológicas sobre los objetos conocidos. Se precisa puntualizar, a este respecto, que los planteamientos racionalistas de Kant se hallaban en consonancia con los presupuestos de la Ilustración, orientados a conseguir la salida del hombre de un estado cultural de minoría de edad, del cuál sólo él era responsable. Para superar dicho estado, tal filósofo había fijado el lema de la Ilustración en el imperativo "atrévete a saber". Schopenhauer se lanzó a implementar lo connotado semánticamente por este imperativo, aventurándose a penetrar en los sótanos más tenebrosos del edificio de la razón. Fue en esos ámbitos inexplorados en donde se encontró con la voluntad, que, según él, se constituye en el cimiento, el móvil y hasta la causa de la razón. Gran parte de los filósofos anteriores a Schopenhauer habían sostenido la primacía del entendimiento sobre la voluntad, llegando a declarar explícitamente que para querer algo resultaba imprescindible conocerlo antes. Por el contrario, se afirma en El mundo como voluntad y representación que el conocimiento va precedido por un ansia previa de obtenerlo. Por consiguiente, 
sería la voluntad la que, en última instancia, impulsaría el deseo de conocer lo que fuere. Según Kant, dicho conocimiento nunca logra penetrar en la "cosa en sí," ni tampoco esclarecerla satisfactoriamente. Schopenhauer, por el contrario, piensa que semejante conocimiento sería, hasta cierto punto, posible, pues la "cosa en sî" es la voluntad, de la cual se puede cobrar una cierta conciencia, mediante lo que él denomina una intuición directa, originaria y genial. Del siguiente modo se refiere Schopenhauer, en El mundo como voluntad y representación, a la diferencia existente entre los posicionamientos de dicho filósofo y los esgrimidos, con anterioridad, por Kant:

[...] mantengo que la esencia interior de cada cosa es voluntad y llamo "voluntad" a la cosa en sí. Con ello se modifica la doctrina kantiana sobre la incognoscibilidad de la cosa en sí, en tanto que, aun cuando ésta no es cognoscible sin más, queda reemplazada para nosotros por el más inmediato de su fenómenos, cuya inmediatez le diferencia radicalmente de todos los demás, habiendo de retrotraerse todo el mundo de los fenómenos a este fenómeno en el que la cosa en sí se presenta con su velo más trasparente y sólo sigue siendo fenómeno en cuanto mi intelecto, lo único capaz de conocer, siempre se distingue del yo volitivo y tampoco de despoja de la forma cognoscitiva del tiempo incluso en la percepción interna (Schopenhauer, 2013: 260).

En conformidad con lo reiterado una y otra vez en El mundo como voluntad y representación, el predominio de la voluntad sobre la razón, ignorado en la filosofía de Kant, no es ajeno a un conocimiento metafísico esencial. De hecho, la necesidad de saber no puede satisfacerse, por completo, partiendo de premisas puramente racionalistas. La metafísica conduce, por tanto, más allá de la ciencia, regida por las exigencias de la razón, aunque en ningún 
caso puede contradecir los resultados de ésta. ${ }^{2}$ De todo esto se deduce que Schopenhauer destruye el paradigma especulativo de procedencia aristotélica, según el cual la razón constituía la más profunda esencia del ser del hombre. Reitera Schopenhauer que dicha esencia no es otra que la voluntad. La representación vendría a ser una muestra objetivizable de ella. Ahora bien, dicho pensador no se limita a advertir tan sólo que la voluntad constituye la esencia del hombre, sino también la esencia de toda la realidad. Tal posicionamiento metafísico pudiera entrar en conflicto con las disquisiciones racionalistas y epistemológicas de Kant, aunque de él existan reminiscencias previas en lo esgrimido por David Hume en An Inquiry Concerning Human Understanding y Tratado de la naturaleza humana, lo mismo que por Baruch Spinoza en Ética. Oponiéndose a Kant, coincidirían Hume, Spinoza y hasta Schopenhauer, al afirmar que detrás de cada acción se encuentra fundamentalmente un cierto impulso convertido en el desencadenante último de lo realizado. Según Kant, es el agente racional el que es capaz de comportarse de un modo determinado, no siguiendo necesariamente sus propias inclinaciones. Advierte dicho filósofo en Fundamentación de la metafísica de las costumbres y Critica de la razón práctica, que la conducta correcta no conducirá necesariamente a la felicidad, pero responde al imperativo categórico, de donde procede el comportamiento moral. ${ }^{3}$ La habilidad para actuar en contra de las inclinaciones promovidas por los impulsos volitivos se suele apoyar en principios de razón práctica, abocados

${ }^{2}$ De acuerdo con lo advertido por Ernst Cassirer en El problema del conocimiento en la filosofía, la voluntad proporciona la clave para tratar la problemática tanto de la física, como también de la misma metafísica.

${ }^{3}$ Se puntualiza en On the Basis of Morality de Schopenhauer que los raciocinios de Fundamentación de la metafísica de las costumbres resultan más inteligibles que los de Crítica de la razón práctica, pues parece que cuando Kant se dedicó a la elaboración de este último estudio sus facultades mentales tal vez se hallaban algo deterioradas debido a su edad avanzada. 
a no dejarse apresar por incentivos emocionales. Si se tuviese en cuenta lo ya explicado, Hume no estaría de acuerdo con dichos juicios éticos, ya que para él la razón no deja de ser la esclava de las pasiones, a las que siempre sirve y obedece. Por su parte, Spinoza argumenta que la verdadera esencia de todo es, de hecho, emocional y se materializa con la ayuda del deseo de perpetuarse en la existencia. ${ }^{4}$ Comentando los posicionamientos éticos de Hume y Spinoza, se afirma en The Riddle of the World, de Barbara Hannan: "If Hume and Spinoza are correct, and Desire lies behind every action, the Kantian idea of a categorical imperative is an absurdity. (Schopenhauer would call it an "iron-wood"). All imperatives are necessarily hypothetical" (Hannan, 2009: 72-73).Mantiene Kant que los seres humanos no se encuentran abocados a conseguir su propia felicidad, sino a cumplir con la obligación dictada por el imperativo categórico. No obstante, resulta paradójico que, al dedicarse alguien a cumplir con su deber, manteniéndose al margen de la consecución de la felicidad, tal fin, en última instancia, se obtiene. Es el propio Aristóteles quien también declara enfáticamente en Ética nicomaquea que no se obtiene la felicidad, simplemente intentando conseguirla, sino como efecto de la práctica de acciones virtuosas. Reitera Kant, sin embargo, que una acción no posee valor moral, a no ser que se realice siguiendo el deber dictaminado, en lugar de seguir el impulso volitivo, del cual convendría preferentemente alejarse. Schopenhauer se sitúa al margen del imperativo categórico, pero parece coincidir, hasta cierto punto, con Kant, al esgrimir que el ideal ético consiste en eliminar el deseo y

\footnotetext{
${ }^{4}$ Según Spinoza, hay dos modalidades de emociones, a saber, las pasivas basadas en ideas oscuras y confusas, y las activas, basadas en ideas claras y distintas. Las emociones pasivas motivan conductas compulsivas y adictivas, contrarias a los intereses reales de cada cual. Las emociones activas motivan conductas encaminadas a promover el interés propio. Parece implicar Spinoza que ambas clases de conducta se encuentran dirigidas emocionalmente, en lugar de originarse en la razón pura.
} 
la voluntad promovida por los placeres que afecten a la existencia individual de uno mismo. No obstante, la afirmación kantiana de que una acción sólo posee valor moral si se lleva a cabo como resultado del sentido del deber, en lugar de alguna modalidad de inclinación, le parece incomprensible a Schopenhauer, quien también advierte que tal deber se aplicaría solamente al ámbito fenoménico y apariencial, sin tener nada que ver con la "cosa en si”. Para dicho pensador, a ese ámbito pertenece simplemente la voluntad individual, mientras que él concede prioridad al comportamiento virtuoso que trasciende cualquier motivación centrada en uno mismo. De hecho afirma Schopenhauer, en $O n$ the Basis of Morality, que la felicidad vendría consistir en la afirmación de la voluntad individual, mientras que la virtud verdadera consiste en su negación. De la siguiente forma explica el discurso raciocinante de The Riddle of the World, el posicionamiento adoptado por Schopenhauer a este respecto y su crítica consiguiente a las propuestas aristotélicas:

Accordingly, virtue can never be a means to happiness. Happiness is affirmation of the individual will, whereas true virtue is a denial of the individual will. Schopenhauer also evidently believes that advocates of eudaimonistic ethics, such as Socrates and Aristotle, failed adequately to answer the egoist's challenge (to the effect that the nonmoral person who gets away with injustice and does not care about anyone but himself is actually happier than the moral man) (Hannah, 2009: 93).

La concepción que de la ética esgrime Schopenhauer presupone que la naturaleza de la "cosa en sî”, es decir, la voluntad, se muestra en las apariencias fenoménicas del mundo como representación. Por consiguiente, se podría alcanzar conocimiento de la "cosa en sí," teniendo en cuenta dicha representación o lo que no es la "cosa en sí". Así pues, la fuente del conocimiento metafísico proviene 
de la observación, utilizada también por las ciencias empíricas, las cuales, en todo caso, se constituirían en objetivizaciones de la "cosa en sí”. Ahora bien, enfatiza Schopenhauer una y otra vez que la voluntad se objetiviza mediante determinados grados o niveles que pudieran muy bien equivaler a las Formas o Ideas platónicas. ${ }^{5} \mathrm{La}$ "cosa en si" o voluntad, aun siendo indiferenciada y universal, se manifiesta y es representada de modo diferenciado y hasta individual. Por otro lado, se precisa no perder de vista, a dicho respecto, que, de acuerdo con lo explicado en El mundo como voluntad y representación, las Ideas y las Formas platónicas no poseen una naturaleza numénica, correspondiente a la "cosa en sí," sino que, de algún modo, se incluirían en el proceso cognitivo, fomentando una cierta objetivización de la voluntad, manifestada a través de los mencionados grados o niveles que tendrían, no obstante, una cierta consistencia ontológica y no son impuestos a la realidad por la mente humana. Antes por el contrario, pertenecen a dicha realidad, esperando ser descubiertos. Para decirlo de otro modo, se puede llegar a entender algo de lo que es la "cosa en si", observando y mirando a aquello que no es la "cosa en sí," la cual se manifiesta en el mundo como representación. Por consiguiente, para promover la especulación metafísica, se precisa tener en cuenta la experiencia empírica. Desviándose de los raciocinios especulativos de Kant, afirma Schopenhauer que la "cosa en sî" es lo que puede ser conocido directamente como voluntad en la inmanencia interior de cada cual y que se manifestaría también hasta en fuerzas físicas, tales como el electromagnetismo y la gravedad.

Explica Rüdiger Safranski a lo largo de lo especulado en Schopenhauer y los años salvajes de la filosofía que, según explicitan los raciocinios esgrimidos por Schopenhauer, el camino hacia la "cosa

\footnotetext{
${ }^{5}$ El nexo que pudiera establecerse entre los razonamientos respectivos de Platón y Schopenhauer ha sido estudiado por Carmen Ramírez Hurtado en "Platón en Schopenhauer: las ideas y la música”.
} 
en sí" termina en la más tenebrosa y espesa inmanencia, consistente en la voluntad sentida a través del propio cuerpo. De acuerdo con lo esgrimido a lo largo de las especulaciones de El mundo como voluntad y representación, los impulsos volitivos son inmanentes, sin quedar reducidos a mera representación externa. Puntualiza dicho pensador que es posible explicar las acciones en las que se involucra el cuerpo mediante nexos causales que ejemplifican lo evidenciado por el principio de razón suficiente, pero sólo en el propio cuerpo se es y se siente lo que será posible explicitar mediante el acto fenoménico de la representación. Dicho de otra forma, la autoexperiencia del cuerpo de uno mismo se convierte en el lugar propio de lo que trasciende la mera representación. Que el mundo exterior sea algo más y algo diferente de tal autoexperiencia se convierte en una certeza reiterada una y otra vez por Schopenhauer. Ahora bien, es en el ser no representado en donde anida la voluntad o la "cosa en si”". Subraya dicho pensador que sus persistentes referencias a la voluntad no constituyen una explicación, sino que muestran tan sólo lo que, al margen lo proporcionado por tal procedimiento, se identifica con el ser. Conviene agregar a todo esto que la autoexperiencia inmediata de la voluntad permite sumergirse en una dimensión metafísica que se halla por debajo de cualquier principio de individuación, teniendo en cuenta no sólo la propia existencia sino también la de otros sujetos cognoscentes y sintientes, sin olvidarse de todo aquello integrado en una exterioridad propensa a ser representada, pero que ayuda a ser consciente de la insignificancia del propio yo frente a la indestructibilidad de la naturaleza defendida con explicitez por Schopenhauer, según lo constatado por Jacques Choron en Death and Western Thought, del modo siguiente: "The doctrine of indestructibility of our 'true nature' seems to be a concession to Schopenhauer's own desire for at least partial immortality. In any event, it is quiet in tune with his conception of will" (Choron, 1978: 174). Si la voluntad 
resulta ser la "cosa en sí," no pertenece al ámbito fenoménico o apariencial y, por consiguiente, se halla al margen de las categorías espacio-temporales impuestas por el sujeto durante la representación de determinados objetos. Al encontrarse la voluntad inmune al desgaste y declive asociado con lo connotado semánticamente por tales categorías epistemológicas, se halla propensa a gozar de una indestructibilidad que no afecta al mencionado ámbito empírico de la exterioridad fenoménica, en donde residen las existencias concretas de sujetos individuales, propensos, no obstante, a experimentar continuamente deseos volitivos, sin solución de continuidad. Puesto que tales impulsos de la voluntad nunca pueden quedar saciados por completo, se suele sufrir una persistente insatisfacción. Incluso, hasta cuando con la muerte individual, se llega al fin de la existencia en el ámbito fenoménico, no por eso desaparece o se siente afectada la voluntad, inserta en las profundidades indestructibles de la "cosa en sí". En conformidad con lo ya advertido, dicha voluntad de vivir, al objetivizarse, se convierte en manifestación singular de sujetos individuales que luchan por la supervivencia en todos los estratos de la vida. Schopenhauer intuye esta voluntad no mediante el conocimiento discursivo, sino con la elucidación del sentimiento interior, fuente de un incesante dolor que afecta al propio ser individual y corpóreo. Dicho sufrimiento hace que la felicidad, presuntamente anhelada por sujetos concretos, sólo pueda ser, en el mejor de los casos, transitoria, pues únicamente, de modo temporal, se podrá suspender la voluntad de vivir que se manifiesta en fenómenos inseparables del deseo y los impulsos, tales como el egoísmo, la autoafirmación o la lucha por los propios intereses. De hecho, es justamente la experiencia estética lo que permite, aunque sólo sea provisionalmente, que el sujeto individual se libere de la presunta esclavitud a la que le somete la voluntad. La clave de tal desenlace se encuentra en la constatación manifiesta de que la experiencia estética pura es desinteresada y 
gracias a ella, se es capaz de vencer o superar los impulsos ocasionados por la autoafirmación y el deseo, manifestaciones representacionales del querer humano, propio de la voluntad inserta en el ámbito metafísico de la "cosa en sí”. A través del desinterés estético, se llegaría a trascender, de algún modo, el ámbito fenoménico, en donde se sienten los irresistibles impulsos padecidos por sujetos individuales. ${ }^{6}$

De acuerdo con lo explicado detalladamente por Bart Vandenabeele en "Aesthetic Disinterestedness in Kant and Schopenhauer," cuando Schopenhauer especula sobre la experiencia estética, a lo largo del discurso raciocinante de El mundo como voluntad y representación, se refiere a la distinción entre lo bello y lo sublime, adelantada por Kant en Crítica del juicio. Un objeto sería bello si se pudiera ver en él la eterna Forma o Idea, transcendiendo así su propia individualidad. Al apreciar la belleza, se conseguiría disfrutar de un estado de contemplación pura y desinteresada. Un objeto es propenso a ser calificado de sublime, no sólo cuando es bello, sino también cuando provoca alguna reacción de hostilidad en el comportamiento humano, pues se le considera, en general, como peligroso, amenazante y hasta incluso lanzado a destruir la propia individualidad de sujetos concretos, que, no obstante, son capaces de superar el miedo por ellos sentido. ${ }^{7}$ A todo esto se precisa agregar que, según lo raciocinado por Schopenhauer, la experiencia estética puede hallarse focalizada en el arte o en la naturaleza. En cualquiera de estas dos modalidades, se llegan a reconocer, al menos inconscientemente, la proximidad y hasta la pertenencia a

${ }^{6}$ El concepto de desinterés, explicado por Schopenhauer, se refiere a una experiencia estética pura, ajena tanto a todo deseo de posesión, como también a comportamientos propensos a ser calificados de utilitaristas.

${ }^{7}$ Para una precisa dilucidación argumentativa de la diferencia existente entre lo proyectado semánticamente por el sentimiento de la belleza y el de lo sublime, convendría consultar las reflexiones ensayísticas proporcionadas por Eugenio Trías en Lo bello y lo siniestro. 
recintos metafísicos universales, que trascenderían la individualidad concreta de cada cual, repleta de impulsos y deseos volitivos, provocadores de una nunca desaparecida insatisfacción. El sujeto humano se hallaría en todo caso en el límite metafísico existente entre el ámbito apariencial, repleto de todo tipo de contingencias fenoménicas y el cerco numénico de la voluntad, identificado con la "cosa en sí," conforme lo ha explicado desde diversos planteamientos dilucidatorios Eugenio Trías en escritos ensayísticos, tales como Los limites del mundo, La aventura filosófica, Lógica del limite, Filosofía del futuro, Etica y condición humana, Ciudad sobre ciudad y El hilo de la verdad. ${ }^{8}$ Esta apreciación del sujeto humano colocado en el límite que hace de frontera entre los respectivos ámbitos del aparecer y el numénico, se reitera una y otra vez a lo largo de los raciocinios de El mundo como voluntad y representación, llegando a influir en la primera parte de la filosofía esgrimida por Ludwig Wittgenstein en Tractatus Logico-Philosophicus. Tanto este pensador, como Schopenhauer, advierten que cuando el sujeto, en cuanto límite del mundo, experimenta un profundo cambio de actitud, también el mundo se transforma. Tal límite se convertiría, así pues, en punto de encuentro entre la exterioridad apariencial y contingente del mundo como representación y la interioridad inmanente del sujeto humano, propenso a tener en cuenta las demandas de la voluntad indestructible y permanente. Dicho sujeto siente miedo a la muerte, en tanto implica el final de la propia individualidad, considerada como representación de la "cosa en sî" o voluntad que, sin embargo y de hecho, es indestructible. De

${ }^{8}$ De acuerdo con lo explicado en Olor a yerba seca de Alejandro Llano, el tema del límite que, según dicho pensador, es un concepto dialéctico, constituye el más difundido y comentado entre los conceptos que Leonardo Polo ha forjado, corregido e incluso hasta abandonado, tal y como se desprende de las disquisiciones esgrimidas en Evidencia y realidad en Descartes, lo mismo que en El acceso del ser, y en escritos posteriores de dicho filósofo. Trías no duda en conectar con Polo, al que considera su maestro. 
la siguiente forma explican los raciocinios expuestos en Death and Western Thought la permanencia definitiva de la voluntad, tal y como es esgrimida por Schopenhauer:

The truth is, according to Schopenhauer, however, that just as the person seeing himself in the mirror does not perish when the mirror is broken, so the will is not affected when the individual perishes. That which is really affected and destroyed by death consciousness and intellect- feels no fear, for it is incapable of having any desire or emotion and is therefore indifferent to being. In other words, whatever the contradictions as far as the sources of the fear of death are concerned, the important thing is that this fear is, according to Schopenhauer, groundless even if one does not share the pessimistic view of life and does not want to escape life. For we do not perish completely (Choron, 1978: 172-173).

De lo argumentado por Schopenhauer se deduce que, aunque se produzca la muerte de un individuo concreto, no por eso desparece la "cosa en sí" o la voluntad universal. El individuo en cuanto tal no trasciende la representación apariencial de algo. Puede muy bien destruirse semejante representación, aun permaneciendo aquello que es representado y que resulta ser, por consiguiente, imperecible. De hecho, la "cosa en si”" ya existía antes del nacimiento del sujeto individual y continuará existiendo también después de su muerte. Este sujeto no se originó de la nada cuando fue concebido o nació y tampoco se convertirá en nada al morir. En todo caso, pudiera afirmarse que el individuo es una representación concreta de la Idea platónica correspondiente a la especie a la que dicho sujeto pertenece y que seguirá existiendo, después de su muerte. Ahora bien, se afirma también en El mundo como voluntad y representación que la voluntad de vivir se halla enraizada en la indestructibilidad y permanencia de dicha Idea, la cual, según reitera Schopenhauer, se identificaría con la naturaleza propiamente 
dicha, sin olvidar que ésta se muestra sumamente cuidadosa con el mantenimiento de la especie, aun ostentando cierta indiferencia respecto a la destrucción de los individuos. A todo esto se precisa agregar que dicho pensador no sólo defiende la indestructibilidad de la especie, sino que incluso se llega a pronunciar también a favor de la conservación de la materia. Por consiguiente, la muerte individual en modo alguno implica una definitiva e ineludible aniquilación total. Conviene puntualizar, no obstante, que para que la naturaleza, la "cosa en sí," y hasta la voluntad continúen existiendo, deben, de alguna forma, llegar a superar los condicionamientos temporales, impuestos por el sujeto trascendental, pero que no necesariamente se encuentran en la realidad empírica. Tal idealismo implicado en la experiencia del tiempo, considerado éste como categoría cognitiva, había sido ya explicado por Kant en Crítica de la razón pura. Al defender la indestructibilidad de la "cosa en sí," Schopenhauer se ve precisado a trascender el ámbito de la mera representación, propio de la existencia individual. La categoría epistemológica del tiempo se hallaría simplemente precisada por dicho ámbito fenoménico, tal y como se advierte en Death and Western Thought, del modo siguiente:

The inference to be drawn from this doctrine seems obvious to Schopenhauer: our existence in time is merely an image of our essential being. Death is merely the end in time of a time-enclosed phenomenon. Man, as thing in itself, is outside of time, timeless, eternal, since for the thing in itself there is no end in time and the word time loses its meaning (Choron, 1978: 177).

Afirma Schopenhauer que la muerte del sujeto individual es tan real como lo fue el comienzo de su vida. Únicamente lo proporcionado por dicho nacimiento y su desarrollo posterior, asociado con la experiencia temporal de la existencia, será lo que destruirá la muerte. Para explicarlo de modo algo diferente, los respectivos 
conceptos de inicio, continuación y cesación son aplicables sólo al ámbito fenoménico y apariencial. Por tanto, la "cosa en sí," considerada por Schopenhauer algunas veces como voluntad y como naturaleza otras, persiste después de la muerte, con independencia de las mencionadas categorías temporales, que resultan ser inconmensurables con la indestructibilidad y permanencia de aquella realidad. Tanto los conceptos de comienzo, como de continuación o final irremisible, son inaplicables a dicho ámbito numénico, el cual existe al margen de cualquier cesación de la vida. Teniendo en cuenta la diferencia, procedente del pensamiento de Kant, entre el fenómeno y la "cosa en sí," se precisa reiterar que el ser humano individual se halla abocado a perecer irremisiblemente en cuanto fenómeno, pero su verdadera naturaleza, identificada con el ámbito numénico de la realidad, no se ve afectada por tal desenlace fatídico. El concepto de indestructibilidad, tal y como lo explica Schopenhauer, implica, por un lado, que lo presuntamente creado de la nada no es lo único que existe y, por otra parte que, aunque con la muerte acaba la vida individual, la existencia de la naturaleza no culmina en dicho desenlace. Así pues, tal pensador estaría de acuerdo con lo esgrimido por Spinoza en Tratado teológico-político, al pronunciarse a favor de la eternidad de la naturaleza. ${ }^{9}$ No obstante, Schopenhauer constata el angustioso sufrimiento experimentado por alguien que, sintiendo la voluntad de vivir, no puede dejar de cobrar conciencia del imperioso y amenazador horizonte de muerte, aunque el conjunto de la naturaleza, en cuanto tal, siga existiendo. El remedio propuesto en El mundo como voluntad y representación para superar tal estado de ánimo consistiría en

\footnotetext{
${ }^{9}$ Para una dilucidación precisa de los propiamente considerados rasgos básicos de la ontología materialista, asentada en el reconocimiento de una ineludible inmanencia, deberían consultarse las aportaciones clarificadoras expuestas por Francisco José Martínez en Materialismo, idea de totalidad y método deductivo en Espinoza y Autoconstitución y libertad.
} 
no perder de vista que las categorías temporales son formas de la intuición, pero que la verdadera naturaleza es indestructible. Este presunto conocimiento de que todo participa de una cierta identidad en dicho nivel numénico de la naturaleza favorece la superación del egoísmo alimentado por el sujeto individual, al intentar sobrevivir a toda costa. Por consiguiente, la desazón procedente de tal ámbito fenoménico perecería, vencida ante el reconocimiento de una indestructible voluntad universal, que transciende identificaciones meramente individualistas, no carentes de un reduccionismo existencial repleto de connotaciones pesimistas.

Mucho se ha especulado sobre el pesimismo asociado directamente al pensamiento de Schopenhauer y contrapuesto, en cierto sentido, al optimismo esgrimido por Gottfried Wilhem Leibniz en Teodicea y Nuevos ensayos sobre el entendimiento humano. Si la posición adoptada por dicho filósofo apunta al hecho de que el mundo existente sería el mejor de todos los posibles, Schopenhauer se pronunciaría exactamente en la dirección opuesta, al advertir que tal mundo sería el peor de todos los posibles. Lo esgrimido a este respecto, por dicho pensador, se halla relacionado con la contingencia irremediable que afecta al ámbito fenoménico de la existencia, en la cual se inserta el sujeto individual y ante la que no cabe evadirse haciéndose ilusiones desviacionistas, pues no hay, de hecho, ningún fin último ni de la vida de cada cual, ni tampoco de la naturaleza. Frente a tal constatación, adoptar un posicionamiento pesimista no consistiría sino en revelar descarnadamente la insensatez de la existencia. Por otro lado, tal pesimismo relacionado con la insatisfacción que acompaña a la voluntad misma implica un padecimiento continuo. A Schopenhauer le mueve no ya el deseo de promover la felicidad, en la que no cree, pero sí al menos el propósito de combatir el dolor, cuya raíz descansa en el yo individual, convertido en fuente de desesperación. Afirma este filósofo que cuando el individuo reflexiona sobre sí mismo, 
la voluntad que yace en su yo le hace creer que es el centro y el núcleo del mundo, por lo que no deja de concederse una relevancia inmensa. Sin embargo, el enfrentamiento de la percepción individual desde dentro con la realidad de la vida exterior hace que dicho sujeto quede ilegítimamente destronado. La frustración radical que le produce al yo dicha confrontación, puede contribuir al encerramiento en un egoísmo mezquino, propenso a convertir al individuo en una tortura para sus semejantes, pues se ve en ellos el principal obstáculo que separa a tal yo de la recompensa que cree merecer, sin, de hecho, recibirla. ${ }^{10}$ Semejante frustración se constituye en una muestra más del sentimiento de pesimismo que, según Schopenhauer, caracteriza a la condición humana, inserta en una voluntad ciega y sin finalidad alguna, convertida en el horizonte existencial de la vida. Por otro lado, tal ausencia de teleología metafísica distancia al pensamiento de este filósofo, de los raciocinios idealistas de Georg Wilhem Friedrich Hegel, quien en Fenomenología del espiritu, Ciencia de la lógica, Lecciones sobre la filosofia de la historia universal y Reason in History se pronunciaba a favor de que la realidad última era el Espíritu, reconociendo también un movimiento histórico dirigido hacia un fin ineludible. Frente al optimismo de la filosofía de Hegel por el futuro, se levanta con Schopenhauer el pesimismo más radical ante el porvenir. Oponiéndose al idealismo hegeliano, Friedrich Nietzsche adoptará muchas ideas de Schopenhauer, aunque no dudará en distanciarse de él y hasta, en cierto sentido, superarlo, extrayendo del principio de la voluntad el concepto completamente novedoso de la vida, materializado en la acción, que se encamina a la consecución del poder, tal y como se deduce de lo argumentado a lo largo de las

${ }^{10} \mathrm{Al}$ no salir el sujeto individual de sí mismo, su encierro contribuye a incrementar la infelicidad e insatisfacción consiguiente. 
disquisiciones recogidas en The Will to Power. ${ }^{11}$ No obstante, conviene puntualizar que la diferencia más notable entre Nietzsche y Schopenhauer estribaría en que de las propuestas intempestivas de Nietzsche se deduce que se quiere porque se vive, mientras que de la filosofía de Schopenhauer se desprende que se vive porque se quiere. ${ }^{12}$ Consecuentemente, Nietzsche otorgaría prioridad motivacional a la vida, en lugar de la preferencia metafísica que a la voluntad le concede Schopenhauer. ${ }^{13}$

A la hora de resumir breve y sinópticamente lo que precede, convendría poner de relieve que el punto de partida de los raciocinios de Schopenhauer proviene del idealismo trascendental esgrimido por Kant, al establecer la diferencia existente entre el ámbito apariencial, al que tiene acceso el conocimiento, y el nivel numénico de la "cosa en sî". Ahora bien, Schopenhauer supera la orientación epistemológica de la filosofía kantiana, interesándose por la permanencia e indestructibilidad metafísica de la voluntad que no deja de poseer una existencia tanto previa como también posterior a las representaciones fenoménicas encarnadas en sujetos

${ }^{11}$ Para una dilucidación nítida y precisa de lo argumentado por Nietzsche convendría consultar las clarificadoras aportaciones recogidas en Not Passion's Slave. Emotions and Choice, Living with Nietzsche. What the Great "Immoralist" Has to Teach Us y True to Our Feelings. What Our Emotions Are Telling Us de Robert C. Solomon.

${ }^{12} \mathrm{Si}$ se tratara de establecer paralelismos y divergencias entre las respectivas argumentaciones de Schopenhauer y Nietzsche, convendría prestar la debida atención a lo aportado pertinentemente por Bart Vandenabeele en "Schopenhauer, Nietzsche, and the Aesthetically Sublime," José Esteban Enguita en "Schopenhauer y el joven Nietzsche: de la metafísica de la voluntad a la metafísica del artista" y Maudemarie Clark en "Suffering and the Affirmation of Life". ${ }^{13}$ En modo alguno Schopenhauer argumenta sus raciocinios, basándose en una dicotomía binaria que enfrentaría a la voluntad, indestructible, de por sí, con la vida. No debería olvidarse a este respecto que, según evidencian las disquisiciones de este pensador, la voluntad, aun siendo ciega y careciendo de fin alguno, se materializa en la afirmación y plenitud de la vida. 
individuales y perecederos. La "cosa en sí" y la voluntad no pertenecen al ámbito fenoménico y, por tanto, se encuentran más allá de las limitaciones impuestas por categorías temporales, abocadas a explicar las experiencias empíricas del inicio, la continuación y la cesación definitiva de sujetos corpóreos que han padecido el dolor procedente de una insatisfacción volitiva no desaparecida en modo alguno. El sentimiento ocasionado por tal estado de desgarro existencial no es otro que el del pesimismo, con el cual se suele asociar a la filosofía de Schopenhauer. Sin embargo, de lo explicado previamente se deriva que tal sentimiento no trasciende el ámbito apariencial de la vida, aunque en el ámbito numénico se precisa reconocer la permanencia indestructible de la voluntad. Por otro lado, no debería desdeńarse el hecho de que las ansias impulsivas procedentes del ejercicio de dicha voluntad no se orientan a la consecución de fin trascendente alguno, sino en todo caso ponen de relieve la inmanencia existencial, constituida en uno de los rasgos más notables que, sin duda alguna, sirven para caracterizar gran parte del pensamiento transicional y hasta pionero de Schopenhauer.

\section{Bibliografía}

Aristóteles, 1985, Ética nicomaquea / Ética eudemia, Madrid, Gredos.

Cassirer, Ernst, 1974, El problema del conocimiento en la filosofía y en la ciencia moderna, México, Fondo de Cultura Económica.

Clark, Maudemarie, 2012, "Suffering and the Affirmation of Life," Journal of Nietzsche Studies, vol. 43, núm. 1, pp. 87-98.

Choron, Jacques, 1978, Death and Western Thought, Nueva York, Collier Books. 
Esteban Enguita, José, 2012, "Schopenhauer y el joven Nietzsche: de la metafísica de la voluntad a la metafísica del artista," Pensamiento: Revista de Investigación e Información Filosófica, vol. 68, núm. 256, pp. 249-272.

Giménez Gracia, Francisco, 2004, La leyenda dorada de la Filosofia, Madrid, Ediciones Libertarias / Prodhufi.

Hannan, Barbara, 2009, The Riddle of the World. A Reconsideration of Schopenhauer's Philosophy, Nueva York, Oxford University Press.

Hegel, Georg Wilhelm Friedrich, 1952, Fenomenología del espiritu, México, Fondo de Cultura Económica.

, 1953, Reason in History, Nueva York, Liberal Art Press. , 1982, Ciencia de la lógica, Buenos Aires, Solar.

, 1986, Lecciones sobre la filosofía de la historia universal, Madrid, Alianza.

Hume, David, 2004, An Inquiry Concerning Human Understanding, Mineola, Nueva York, Dover Publishers.

, 1988, Tratado de la naturaleza humana, Madrid, Tecnos.

Kant, Immanuel, 1978, Crítica de la razón pura, Madrid, Alfaguara. Madrid, Espasa Calpe.

, 1977, Critica del juicio, Madrid, Espasa Calpe.

, 1975, Crítica de la razón práctica, Madrid, Espasa Calpe.

Leibniz, Gottfried Wilhem, 1946, Teodicea, Buenos Aires, Editorial Claridad.

, 1977, Nuevos ensayos sobre el entendimiento humano, Madrid, Editorial Nacional. 
Llano, Alejandro, 2008, Olor a yerba seca. Memorias, Ediciones Encuentro, Madrid.

Martínez, Francisco José, 1988, Materialismo, idea de totalidad y método deductivo en Espinoza, Madrid, UNED.

, 2007, Autoconstitución y libertad. Ontología y politica en Espinosa, Barcelona, Anthropos.

Nietzsche, Friedrich, 1968, The Will to Power, Nueva York, Vintage Books.

Polo, Leonardo, 2007, Esencia y realidad en Descartes, Pamplona, Eunsa.

,2004, El acceso al ser, Pamplona, Eunsa.

Ramírez Hurtado, Carmen, 1991, "Platón en Schopenhauer: las ideas y la música" Studium: Geografia, historia, arte y filosofía, núm. 3, pp. 231-240.

Safranski, Rüdiger, 2011, Schopenhauer y los años salvajes de la filosofía, Barcelona, Tusquets.

Schopenhauer, Arthur, 2013, El mundo como voluntad y representación 2. Complementos, Madrid, Alianza.

, 1995, On the Basis of Morality, Indianapolis, Hackett.

Solomon, Robert C., 2003, Not Passion's Slave. Emotions and Choice, Nueva York, Oxford University Press.

, 2003, Living with Nietzsche. What the Great "Immoralist" Has to Teach Us, Nueva York, Oxford University Press.

, 2007, True to Our Feelings. What Our Emotions Are Telling $U s$, Nueva York, Oxford University Press.

Spinoza, Baruch, 1987, Ética, Madrid, Alianza.

, 1986, Tratado teológico-politico, Madrid, Alianza.

Trías, Eugenio, 1982, Lo bello y lo siniestro, Barcelona, Seix Barral. 
, 1985, Los límites del mundo, Barcelona, Ariel.

, 1988, La aventura filosófica, Madrid, Mondadori.

, 1991a, Filosofía del futuro, Barcelona, Destino.

, 1991b, Lógica del límite, Barcelona, Destino.

, 2000, Ética y condición humana, Barcelona, Península.

, 2001, Ciudad sobre ciudad. Arte, religión y ética en el cambio de milenio, Barcelona, Destino.

, 2004, El hilo de la verdad, Barcelona, Destino.

Vandenabeele, Bart, 2003, "Schopenhauer, Nietszche and the Aesthetically Sublime," The Journal of Aesthetic Education, vol. 37, núm. 1, pp. 90-116.

, 2012, "Aesthetic Disinterestedness in Kant and Schopenhauer," Estetika: The Central European Journal of Aesthetics, vol. 49, núm. 1, pp. 45-70.

Wittgenstein, Ludwig, 1974, Tractatus Logico-Philosophicus, Londres, Routledge and Kegan Paul.

(fecha de aceptación del artículo) 
